\title{
AN EXPLORATORY STUDY TO ASSESS THE KNOWLEDGE AND PRACTICES OF MOTHERS REGARDING WEANING DIET IN A SELECTED HOSPITAL, LUDHIANA, PUNJAB
}

\author{
Minakshi John¹, Ashish Ahuja², Veena Barkat³, Sudesh David', Anju Bhagtana ${ }^{5}$ \\ ${ }^{1}$ Associate Professor of Nursing, College of Nursing, DMC Hospital, Ludhiana. \\ ${ }^{2}$ Associate Professor, Department of Surgery, DMC Hospital, Ludhiana. \\ ${ }^{3}$ Ex. Professor of Nursing, Christian Medical College \& Hospital, Ludhiana. \\ 4 Principal \& Professor, GTB College of Nursing, Ludhiana. \\ ${ }^{5}$ Senior Resident, Department of Surgery, DMC Hospital, Ludhiana.
}

\section{ABSTRACT}

The present study was conducted to assess the knowledge and practices of mothers regarding weaning diet. The study aims at improving knowledge and practices of mothers regarding weaning diet and identifying the deficit areas related to weaning diet. An exploratory approach was applied using purposive sampling; 100 mothers of children 6 months to 2 years were selected. Education of mothers and family income showed significant impact on practices of mothers regarding weaning diet. Conclusion were drawn based on the findings of the study, i.e. most of the mothers had average knowledge regarding weaning diet and maximum mothers follow unsatisfactory practice. Maximum number of mothers had higher knowledge score in administration area and minimum knowledge score in introduction area, whereas maximum number of mothers had higher practice score in introduction area and minimum in preparation area.

\section{KEYWORDS}

Infants, Weaning, Mothers, Feed.

HOW TO CITE THIS ARTICLE: John M, Ahuja A, Barkat V, et al. An exploratory study to assess the knowledge and practices of mothers regarding weaning diet in a selected hospital, Ludhiana, Punjab. J. Evolution Med. Dent. Sci. 2016;5(39):2359-2362, DOI: $10.14260 /$ jemds/2016/548

\section{INTRODUCTION}

The birth of the child is a significant event in the family. The health of a growing child is always a matter of great concern to the parents. Early childhood constitutes the most crucial period of life when the foundation is laid for cognitive, social, emotional, physical/motor development and cumulative lifelong learning. The physical health of the child is important, because it is associated with mental and social development. Most of the children have not been protected over years, which led them to be the most vulnerable, dependent and least powerful population group in India (Sasikala and Jayagouri, 2008). ${ }^{1}$ Nutrition has a major effect on health. Nutrition refers to the availability of energy and nutrients to the body's cells in relation to body requirements. It is the process of being nourished by which a living organism assimilates food and uses it for growth, development and maintenance. Better nutrition means stronger immune systems, less illness, better health and learning capabilities. Better nutrition is a prime entry point towards ending poverty and a milestone towards achieving better quality of life (Raju SM, 2010).2

Weaning is defined as the introduction of foods other than the breast milk into an infant's diet, while slowly reducing breast feeding. It is usually observed that significant emphasis is placed by mothers in the beginning of the weaning period, but there are no added physiological, psychological, economical or nutritional advantages of early weaning. ${ }^{3}$ Delayed weaning can lead to serious health complications

Financial or Other, Competing Interest: None.

Submission 30-03-2016, Peer Review 26-04-2016,

Acceptance 02-05-2016, Published 13-05-2016.

Corresponding Author:

Dr. Ashish Ahuja,

\#132/1, Rani Jhansi Road, Civil Lines,

Ludhiana, Punjab.

E-mail: drahuja17@gmail.com

DOI: $10.14260 /$ jemds $/ 2016 / 548$ for the infants, because after the 6 months of age breast milk alone is not sufficient both in quality and quantity to meet the nutritional requirements of the child-especially for the energy and micronutrients. Breast milk is notably insufficient in iron, zinc and vit-A requirement of the nursing baby. ${ }^{4}$ Protein Energy Malnutrition (PEM) is reported to show an association with delayed weaning too, which is comprised of mainly neurological manifestations. Factors affecting weaning practices vary according to the socio-economic stratification of the population and include education, customs, beliefs and taboos. ${ }^{5}$

WHO. ${ }^{6}$ recommends breastfeeding exclusively for the first four to six months. For the first few months of life, the baby will receive all the nutrition and energy his or her body needs from breast. However, once baby is six months old, he/she may not get all the calories, iron and other nutrients. They need it from milk alone or may require increasingly large or frequent feeds to do so. United Kingdom (UK) Department of Health recommended that solids should be introduced at around six months for breast fed and infants. Do not give solid food earlier than six months unless advised by doctor. Feeding the baby solid food too early may lead to overfeeding and overweight. So six months is a good time to introduce and then gradually increase the amount of solid foods you give to baby.

Researchers suggest that babies in Ireland are given solid foods before the recommended age and studies conducted have shown a link between the early introduction of solids and health risks such as food intolerance, excess weight gain and Diabetes. ${ }^{7}$ Other studies have shown that late introduction of solid foods was associated with increased risk of allergic sensitization of food (Specifically oats and eggs) and inhaled allergens (Specifically potatoes and fish). ${ }^{8}$

Most of the researchers have focused on the actual recommendations and the timing of starting the solids there has been little done on the weaning advice provided by health professionals routinely caring for infants during this 
important period in their development, even though a recent studies suggest that the influence of health professionals on infant weaning practices has the potential to be as great as cultural values or material resources. ${ }^{9}$

Jamaluddin. ${ }^{10}$ stated that nutritional educated mothers can bring up their children in a healthier way. Improving breast feeding techniques not can also decrease the frequency of gastroenteritis and respiratory infections and reduce the number of infant deaths.

\section{AIMS AND OBJECTIVES}

1. To assess the knowledge of mothers regarding weaning diet.

2. To assess the practices of mothers regarding weaning diet.

3. To find out the relationship of knowledge of mothers with selected variables age, education, occupation, number of children (Parity), religion, type of family, income and source of information.

4. To find out the relationship of practices of mothers with selected variables age, education, occupation, number of children (Parity), religion, type of family, income and source of information.

5. To identify the deficit areas (Introduction, preparation and administration) of weaning diet and prepare the guidelines.

\section{Review of Literature}

Studies have shown that mothers lack knowledge regarding nutritional needs of children. Majority of studies have shown that demographic characteristics significantly affect mother's knowledge regarding nutrition. Study done to assess the impact of educational interventions on knowledge of mothers regarding child care and nutrition proved that there was significant improvement in knowledge of mothers with educational programmes on nutrition (Sharma S and Nagar S, 2006). ${ }^{11}$

Kabir I. ${ }^{12}$ did study conducted in the rural population reported that according to Gomez classification, 96\% of children had varying degrees of Protein Energy Malnutrition (PEM) (28,4\% mild, 58.2\% moderate and 9.2\% severe). Mothers follow faulty feeding practices and have inadequate knowledge regarding nutrition knowledge. Wilson et al ${ }^{13}$ reported that introducing solids before 15 weeks is associated with an increased likelihood of respiratory illness, particularly wheeze and persistent cough. ${ }^{14}$

Manju did study to assess the knowledge and practices regarding breast feeding and weaning. Results indicated that only half the mothers breastfed their babies at first. Breast feeding was stopped when the child was 3-6 months; top feeding and solid supplements were initiated at 4-6 months, mainly commercial baby foods were used for weaning. Most mothers avoided 'dals' for the child, because they were believed to be difficult to digest; $50 \%$ of the mothers were not in favour of feeding the sick child with small frequent meals. Period of weaning is a transitional phase. Change can take place without risk only if proper foodstuffs are available, which are nutritionally adequate, easily digestible, hygienically safe and easily taken by the infants.

An exploratory qualitative investigation was done to determine the feeding and weaning practices, knowledge and attitude regarding nutrition of mothers of children up to 3year-old attending baby clinics in the Moretele district (South
Africa) in March 2002. Trained moderators using a pre-tested structured in review schedule. The data analysis revealed that inadequate nutrition knowledge and adherence to cultural practices lead to poor quality feeding practice. ${ }^{15}$

\section{METHODOLOGY}

\section{Research Approach and Research Design}

An exploratory survey with descriptive approach was used to assess the knowledge and practices of mothers regarding weaning diet.

\section{Sample and Sampling Technique}

100 mothers having children of 6 months to 2 years of age visiting Paediatric Outpatient Department and mothers whose children are admitted in paediatric ward, Christian Medical College and Hospital selected. Purposive sampling technique was used to choose the sample.

\section{Description of Tool}

\section{Part I}

Socio-demographic profile consists of age, education, occupation, number of children (Parity), religion, type of family, income and source of information.

\section{Part II}

It consists of Self-Structured questionnaire to assess knowledge of mothers regarding weaning diet. These items consist of 16 multiple choice questions and 20 questions in the checklist. Each question consists of one correct answer among the three choices and each correct answer carries one mark each.

\section{Criterion Measures}

Total Questions: 36 (Part II=16 Questions and Part III=20 Questions).

\section{Knowledge Score}

\begin{tabular}{|c|c|c|c|}
\hline \multicolumn{4}{|c|}{ Maximum Score $=16$} \\
\hline Levels & & Scores & Percentage \\
\hline Good & : & $12-16$ & $(\geq 70 \%)$ \\
\hline Average & : & $6-11$ & $(50-70 \%)$ \\
\hline Below average & : & $\leq 5$ & $(\leq 50 \%)$ \\
\hline
\end{tabular}

\section{Practice Score}

\begin{tabular}{|c|c|c|c|}
\hline \multicolumn{4}{|c|}{ Maximum Score $=20$} \\
\hline \multicolumn{4}{|c|}{ Minimum Score $=0$} \\
\hline Levels & & Scores & Percentage \\
\hline Satisfactory & : & $\geq 16$ & $(\geq 80 \%)$ \\
\hline Unsatisfactory & : & $\leq 16$ & $(\leq 80 \%)$ \\
\hline
\end{tabular}

\section{Data Collection Procedure}

Data collection procedure of the study was carried out in Paediatric ward and paediatric OPD of a selected Hospital. SelfStructured questionnaire and Interview method was used by the investigator to collect data from the mothers of children, age group 6 months to 2 years. 


\section{Major Findings}

Majority of mothers fall in 20-25 years of age group. According to education, most of the women fall in $5^{\text {th }}$ to $8^{\text {th }}$ standard category. According to occupation, majority of women are housewives. According to number of children majority of women have two children, whereas according to religion maximum mothers are from Hindu religion. According to type of family, maximum mothers are from joint family. According to income maximum mothers fall in Rs. 5001 - Rs. 10,000 per month income group and according to source of information maximum mothers have information regarding weaning diet from family and friends.

Maximum number of mothers had average knowledge regarding weaning diet. Maximum number of mothers had higher knowledge in administration area and minimum knowledge in introduction area. Maximum number of mothers had unsatisfactory practices regarding weaning diet. Maximum number of mothers had higher practices in introduction area and minimum in preparation area. The knowledge of mothers regarding weaning diet increases, so does the practices improve. Maximum mothers having average knowledge regarding weaning diet fall under $10^{\text {th }}$ to $10+2$ category and there was no association of education of mothers with knowledge regarding weaning diet. Maximum percentage of women having average knowledge fall under labourer category; there was no association of occupation with knowledge regarding weaning diet. Mothers who had 2 children had better knowledge than mothers who had one or three and above children.

But there was no association of number of children (Parity) with knowledge of mothers regarding weaning diet. There was no association of religion with knowledge regarding weaning diet. There was no association of type of family with knowledge weaning diet. There was no association of income with knowledge. Mothers who were in service had less unsatisfactory practices comparative to labourer and housewives; there was no association of occupation with practices regarding weaning diet. There was no association of number of children or parity with practices with weaning diet. There was no association of religion with practices of weaning diet. There was no association of type of family with practices of weaning diet. There was no association of income with practices of weaning diet. Mothers who had knowledge from media had higher unsatisfactory practices as compared to mothers who had knowledge from family/friends.

\begin{tabular}{|c|c|c|c|}
\hline \multirow{2}{*}{$\begin{array}{c}\text { Level of } \\
\text { Knowledge }\end{array}$} & \multicolumn{3}{|c|}{ Knowledge Score } \\
\cline { 2 - 4 } & Score & N & \% \\
\hline Good $>75 \%$ & $>12$ & 19 & 19 \\
\hline Average $(50-75 \%)$ & $8-12$ & 72 & 72 \\
\hline Below $(<50 \%)$ & $<8$ & 9 & 9 \\
\hline
\end{tabular}

Table 1: Frequency and Percentage Distribution of Mothers According to Level of Knowledge Regarding Weaning Diet

$\mathrm{N}=100$

Maximum Score $=16$

Minimum Score $=0$

\begin{tabular}{|c|c|c|c|}
\hline Level of & \multicolumn{3}{|c|}{ Practices Score } \\
\cline { 2 - 4 } Practices & Score & N & $\mathbf{\%}$ \\
\hline Satisfactory $(>80 \%)$ & $(16-20)$ & 25 & 25 \\
\hline Unsatisfactory $(<80 \%)$ & $(<16)$ & 75 & 75 \\
\hline Table 2: Frequency and Percentage Distribution of \\
Mothers According to Level of Practices \\
Regarding Weaning Diet \\
\hline
\end{tabular}

$\mathrm{N}=100$

Maximum Score $=20$

Minimum Score $=0$

\section{IMPLICATIONS}

\section{Nursing Education}

- The paediatrics nursing and community health nursing curriculum for all level of nursing students should give more emphasis on knowledge and practices of mothers regarding weaning diet to prevent malnutrition and micronutrient.

- Formal and informal teaching should be conducted by nursing students in hospitals and community areas for promoting satisfactory weaning practices.

- Nursing professional working in hospital and community area can find opportunity to teach and improve the knowledge and practices of the mothers regarding weaning diet based on the results of the study.

\section{Nursing Service}

- The healthy practices of mothers regarding weaning diet need to be encouraged through regular health education by health team members.

- Nursing students should actively conduct research in this field, so as to become aware of weaning practices in the community as well as in hospital.

\section{Nursing Administration}

- Nursing administration at hospital level and community health should on time to time evaluate the mothers' knowledge and practices regarding weaning diet.

- In-service education should be concluded for health personnel to educate them for promoting satisfactory practices regarding weaning diet.

\section{RECOMMENDATIONS}

Based on the findings, the following recommendations were offered for future research.

- Comparative study can be carried out to assess weaning practices among mothers in urban and rural community.

- A study can be carried out to find out the factors affecting the weaning diet.

- The tool used for assessing knowledge and practices of mothers can be further developed and field tested for standardizing it.

- Mass media, health education program should be arranged to educate the mothers about knowledge and practices regarding weaning.

\section{REFERENCES}

1. Sasikala T, Jayagouri S. Effectiveness of structure teaching programme on acute respiratory infection. Nightingale Nursing Times 2008;4(3):12-4. 
2. Raju SM. Nutrition and biochemistry for nurses. New Delhi: Jaypee Brothers. 2010;1 $1^{\text {st }}$ ed.

3. Aregai WG. Determinants of weaning practices. Ethiop J Health Dev 2000;14(2):183-9.

4. Ahmad Z, Daw W, Isa A. Breast feeding and weaning practices in rural communities of Kelantan. Mal J Nutr 1996;2(2):148-54.

5. Odebode TO, Odebode SO. Protein energy malnutrition and the nervous system: the impact of socioeconomic condition, weaning practice, infection and food intake, an experience in Nigeria. Pakistan Journal of Nutrition 2005;4(5):304-9.

6. World Health Organisation. Global strategy for infant and young child feeding. Geneva: WHO; 2001.

7. Department of health: infant feeding recommendations. 2008.

[http://www.breastfeeding.nhs.uk/en/docs/FINAL_QA.p df].

8. Tarrant R. An investigation of the diets of infants born in Ireland during the first six months of life. In Doctoral Thesis Dublin; Dublin Institute of Technology; 2008.
9. Nwaru BI, Erkkola $\mathrm{M}$, Ahonen $\mathrm{S}$, et al. Age at the introduction of solid foods during the first year and allergic sensitization at age 5 years. Paediatrics 2010;125(1):50-9.

10. Campbell ND, Soeken KL, Rankin EAD. Infant weaning patterns and related maternal-infant health outcomes. Public Health Nursing 1986;3(1):57-63.

11. Sharma S, Nagar S. Impact of educational intervention on knowledge of mothers regarding child care and nutrition. Journal of social Science 2006;12(2):139-42.

12. Azte KM, Shehla G, Sidra MT, et al. Evaluation of nutritional knowledge of mothers about their children. Gomal Journal of Medical Sciences 2007;5(1):17-21.

13. Iqbal Hossain M, Yasmin R, Kabir I. Nutritional and immunisation status, weaning practices and socioeconomic conditions of under five children in three villages of Bangladesh. Indian J Public Health 1999;43(1):37-41.

14. Wilson AC, Forsyth JS, Greene SA, et al. Relation of infant diet to childhood health: seven year follow up of cohort of children in Dundee infant feeding study. British Medical Journal 1998;316:21-5.

15. Kruger R, Gericke GJ. A qualitative exploration of rural feeding and weaning practices, knowledge and attitude on nutrition. Public health nutrition 2003;6(2):217-23. 